\title{
BMJ Open A longitudinal general population- based study of job strain and risk for coronary heart disease and stroke in Swedish men
}

\author{
Kjell Torén, ${ }^{1,2}$ Linus Schiöler, ${ }^{1}$ W K Giang, ${ }^{3}$ Masuma Novak, ${ }^{3}$ Mia Söderberg, ${ }^{1}$ \\ Annika Rosengren ${ }^{3}$
}

To cite: Torén K, Schiöler L, Giang WK, et al. A

longitudinal general population-based study of job strain and risk for coronary heart disease and stroke in Swedish men. BMJ Open 2014;4:e004355.

doi:10.1136/bmjopen-2013004355

- Prepublication history for this paper is available online. To view these files please visit the journal online (http://dx.doi.org/10.1136/ bmjopen-2013-004355).

Received 29 October 2013 Revised 7 February 2014 Accepted 10 February 2014



\footnotetext{
${ }^{1}$ Section of Occupational and Environmental Medicine, Institute of Medicine, Sahlgrenska Academy, University of Gothenburg, Gothenburg, Sweden ${ }^{2}$ Department of Occupational Medicine, Respiratory Diseases and Toxicology, University of Perugia,

Perugia, Italy

${ }^{3}$ Department of Molecular and Clinical Medicine, Institute of Medicine, Sahlgrenska Academy, University of Gothenburg, Gothenburg, Sweden
}

Correspondence to Dr Kjell Torén; Kjell.Toren@amm.gu.se

\section{ABSTRACT}

Objectives: The aim was to investigate whether psychosocial stress based on the job-demand-control (JDC) model increased the risk for coronary heart disease (CHD) and stroke.

Setting: Swedish men.

Participants: The Primary Prevention Study (PPS) comprises 6070 men born between 1915 and 1925 free from previous history of $\mathrm{CHD}$ and stroke at baseline (1974-1977). Psychosocial workplace exposure was assessed using a job-exposure matrix (JEM) for the JDC model based on occupation at baseline. The participants were followed from baseline examination, until death, until hospital discharge or until 75 years of age, whichever occurred first, using the Swedish national register on cause of death and the Swedish hospital discharge register for non-fatal and fatal stroke and CHD events. Cox regression models were used with stroke or $\mathrm{CHD}$ as the outcome, using JDC model and age as explanatory variables, as well as stratified models with regard to smoking, self-reported stress, socioeconomic status, obesity, hypertension and diabetes.

Primary and secondary outcome measures: Risk for stroke and CHD.

Results: There was an increased risk (HR) for $\mathrm{CHD}$ in relation to high strain (HR $1.31,95 \% \mathrm{Cl} 1.01$ to 1.70 ). The risk was further increased among ever-smokers and among blue-collar workers. There was a relation between low control and increased risk for CHD ( $\mathrm{HR} 1.19,95 \% \mathrm{Cl}$ 1.06 to 1.35 ). There was no increased risk for stroke in any of the JDC categories.

Conclusions: Exposure to occupational psychosocial stress defined as job strain or low control increased the risk for CHD, especially among smokers and blue-collar workers. There was no increased risk for stroke in any of the JDC categories.

\section{INTRODUCTION}

During the past decades, a growing body of evidence has accumulated showing that psychosocial stress is associated with adverse health outcomes, especially coronary heart

\section{Strengths and limitations of this study}

- Job strain increases the risk for coronary heart disease $(\mathrm{CHD})$, but the relation to stroke is uncertain. There is a need for longitudinal general population-based studies in this field.

- This study confirms that job strain increases the risk for CHD, but the risk seems to be limited to blue-collar workers. There was no clear relation between job strain and risk for stroke.

disease (CHD). ${ }^{1}$ Psychosocial stress as a risk factor has been studied as a general factor as well as linked to the workplace. The most studied definition of workplace-related stress has been the job-demand-control (JDC) model. ${ }^{2}$ According to Karasek, the job demand variable constitutes volume and intensity of workload and job control referred to the working individual's potential control over pace and content of their tasks. ${ }^{2}$ In this model, it is postulated that the combination of high demands and low decision latitude at work results in high strain (job strain) which increases the risk of cardiovascular diseases. There are studies showing that high strain is associated with a doubled risk of CHD. However, in a recent meta-analysis of 13 studies, the association was rather modest (HR 1.23). The used models were adjusted for gender and age, and in some cases also for socioeconomic status. The authors concluded that adjustments for lifestyle factors did not substantially affect the association. ${ }^{3}$ However, in an additional paper from the previous meta-analysis, it was found that the risk of CHD was further increased among participants with job strain in combination with current smoking, being obese or reporting low physical activity. ${ }^{4}$ Hence, it seems clear that job strain is associated with 
an increased risk for CHD, and there may also exist interactions with lifestyle factors.

There are studies indicating that self-reported psychosocial stress increases the risk for stroke. ${ }^{5}{ }^{6}$ However, the evidence between occupational exposure to psychosocial stress and stroke is less clear. There are two longitudinal studies showing slightly increased risk for stroke associated with low control. ${ }^{7} 8$ One study showed an increased risk in working Finnish men, ${ }^{7}$ and in another study based on the Swedish working population, there was an increased risk among women, but not among men. ${ }^{8}$ The association with job strain is also unclear; two studies in women show an association, ${ }^{9}{ }^{10}$ and one study in the general population did not find any association, either among women or men. ${ }^{11}$ In a prospective general population-based study from Japan, it was found that men, but not women, with high-strain job had an increased risk for stroke, with more than doubled risks among those with active, passive or high-strain jobs. ${ }^{12}$

The aim of the present study was to investigate whether psychosocial stress based on the JDC model increased the risk for CHD and stroke. The study base is a longitudinal general population study of 6070 Swedish men followed from baseline examination (1974-1977), until death, until hospital discharge or until 75 years of age, whichever occurred first, using the Swedish national register on cause of death and the Swedish hospital discharge register.

\section{METHODS}

Study population

The Primary Prevention Study (PPS) is a populationbased cohort study from Gothenburg, Sweden. It was established in 1970 as previously described. ${ }^{13}$ The source population comprised all men living in Gothenburg born between 1915 and 1925. The initial study population was a random sample of 10000 men, and 7494 men (75\% of the sample) participated in screening examinations between January 1970 and March $1973 .{ }^{14} 15$ Three years later, 1974-1977, a clinical follow-up investigation was performed where 7133 men participated. In the present study, we are using data from the first follow-up investigation, because in that round there were complete occupational data. All participants gave their informed consent to participate in the study.

The current occupation at baseline (1974-1977) was classified at three-digit level according to the Nordic Classification of Occupations, NYK-74. ${ }^{16}$ For assessing the psychosocial workplace exposure, we used a previously published job-exposure matrix (JEM). ${ }^{17}{ }^{18}$ This JEM was developed in late 1970s based on information from large Swedish population surveys where around 12000 randomly selected participants aged 25-74 years were classified for psychological demands and decision latitude. The JEM gives separate estimates of demand and control for 261 occupations separated into gender and age (25-44 and 45-74). Socioeconomic status, high or low, was obtained based on one-digit level of occupations, that is, blue-collar versus white-collar workers.

Psychological job demands and decision latitude were explored with four items each. All items were scored using a scale, ${ }^{1-10}$ with a score of 10 indicating high psychological demands or high decision latitude. Each participant was assigned a certain score based on occupation and age. The scores were then dichotomised into high and low, using the median of the distribution as cut-off. Combining demand and control with the median cut-offs divides the participants into four categorical quadrants: high strain (high demand-low control), active (high demand-high control), passive (low demand-low control) and low strain (low demand-high control).

In the present study, there was information at baseline about age, country of birth (Sweden/other), body mass index (BMI), serum cholesterol (s-cholesterol) level, systolic blood pressure, diastolic blood pressure, use of antihypertensive medication (yes/no), history of diabetes (yes/no), CHD (yes/no), hypertension (yes/no) or stroke (yes/no) at baseline, self-reported stress and smoking as previously described. ${ }^{19}$

Participants with CHD or stroke at baseline (19741977) were excluded resulting in a study population of 6070 participants (table 1). Based on unique personal identification numbers, participants were followed from the date of their baseline examination until death, until hospital discharge or until 75 years of age, whichever occurred first, using the Swedish national register on cause of death and the Swedish hospital discharge register. The hospital discharge register has operated on a nationwide basis since 1987, but all discharges from Gothenburg hospitals have been entered in the national register since 1970 (except for 1976, because of a legislative change for that year). Additional data from the Gothenburg stroke register were used to identify strokes from the start of the study until 1983. The International Classification of Disease (ICD) codes listed in the registries were used to identify stroke events (non-fatal and fatal events) and CHD during the entire follow-up period. The eighth version of the ICD code was used until 1986, ICD-9 was used from 1987 to 1996 and ICD-10 was used from 1997 onwards. Ischaemic stroke was defined as ICD codes 431-438 and I61-I69. Non-fatal CHD was defined as 410 and I21. Fatal CHD was defined as 410-414 and I20-I25. Each type of event was treated separately, and only the first event of each type was used in the analysis.

\section{Statistical analysis}

Descriptive statistics are presented as percentages or mean values with SDs. All analyses were performed using the SAS statistical package (V.9.3) and R (V.3.0.1). The material was analysed with Cox regression models using SAS (the PHREG procedure). The proportional hazards assumptions were investigated using tests and plots based on weighted residuals $^{20}$ using the $\mathrm{R}$ package Survival. All assumptions were found reasonable except for the analysis of baseline 
Table 1 Baseline characteristics of a general population study of 6070 Swedish men

\begin{tabular}{|c|c|c|c|c|c|}
\hline & Active $\mathrm{N}=2357$ & $\begin{array}{l}\text { High } \\
\text { strainN=671 }\end{array}$ & $\begin{array}{l}\text { Low } \\
\text { strainN=679 }\end{array}$ & PassiveN=2363 & OverallN $=6070$ \\
\hline Age, years (SD) & $55.2(2.1)$ & $55.3(2)$ & $55.2(2)$ & $55.4(2)$ & $55.3(2.1)$ \\
\hline Cholesterol, mmol/L (SD) & $6.37(1.05)$ & $6.45(1.1)$ & $6.37(0.99)$ & $6.43(1.05)$ & $6.4(1.05)$ \\
\hline SBP, mm Hg (SD) & $145.1(19.5)$ & $147.2(20.5)$ & $145.2(18.8)$ & $146.8(19.7)$ & $146(19.6)$ \\
\hline BMI, $\mathrm{kg} / \mathrm{m}^{2}$ (SD) & $25.5(3.1)$ & $25.6(3.4)$ & $25.8(3.2)$ & $25.8(3.4)$ & $25.6(3.3)$ \\
\hline Diabetes, \% (N) & $2.8(65)$ & $3.6(24)$ & $2.5(17)$ & $2.7(64)$ & $2.8(170)$ \\
\hline Hypertension, \% (N) & $21.8(512)$ & $23.9(160)$ & $22.5(152)$ & $21.9(517)$ & $22.1(1341)$ \\
\hline Hypertensive medication, \% (N) & $15.2(358)$ & $16.5(111)$ & $14.6(99)$ & 13.9 (328) & $14.8(896)$ \\
\hline White-collar Job, \% (N) & $98.3(2316)$ & 26.7 (179) & $29.5(200)$ & $15.0(355)$ & $36.8(2177)$ \\
\hline Self-reported stress at baseline, \% (N) & $43.7(1014)$ & $36.5(236)$ & $30.9(205)$ & $31.5(722)$ & $36.8(2177)$ \\
\hline \multicolumn{6}{|c|}{ Smoking status, \% (N) } \\
\hline NeverN=1437 & $25.8(607)$ & $21(141)$ & $25.2(171)$ & $21.9(518)$ & $23.7(1437)$ \\
\hline CurrentN=2460 & $37.3(879)$ & $47.4(318)$ & $39.0(265)$ & 42.2 (998) & $40.5(2460)$ \\
\hline FormerN=1890 & $32.7(771)$ & $27(181)$ & $31.4(213)$ & $30.7(725)$ & $31.1(1890)$ \\
\hline UnknownN=283 & $4.2(100)$ & $4.6(31)$ & $4.4(30)$ & $5.2(122)$ & $4.7(283)$ \\
\hline \multicolumn{6}{|l|}{$\begin{array}{l}\text { Number of events (mean age, years, } \\
\text { at event) }\end{array}$} \\
\hline Coronary heart disease & $384(66.2)$ & $131(66.4)$ & $104(65.9)$ & $433(65.9)$ & $1052(66.0)$ \\
\hline Stroke & 208 & 64 & 65 & 212 & 549 \\
\hline \multicolumn{6}{|l|}{ Mean follow-up time, months } \\
\hline Coronary heart disease & 200 & 193 & 199 & 192 & 196 \\
\hline Stroke & 204 & 195 & 203 & 197 & 200 \\
\hline
\end{tabular}

diabetes. Hospital care or mortality (whatever came first) from stroke or CHD was the event, and time was measured as months since baseline. The observation period stopped at the age of 75 . In the crude model, HRs were calculated using the JDC model and age as explanatory variables. The low-strain group was used as reference group. There were also models using high-strain participants versus all other participants as an independent variable. There were also separate models stratifying for ever-smoking and neversmoking, adiposity (BMI $\geq 30$ ) or not, hypertension or not at baseline and diabetes or not, self-reported stress or not at baseline and finally status as white-collar or blue-collar worker at baseline. There was also one model with 5 years latency time, that is, excluding participant with any event occurring during the first 5 years during the follow-up.

\section{RESULTS}

For the follow-up period, there were 1052 events due to CHD. The Cox regression models adjusted for age showed an increased risk (HR) for CHD in relation to high job strain (HR 1.31, 95\% CI 1.01 to 1.70 ; table 2 ). In the stratified analysis, high strain was associated with an even slightly higher risk for CHD among ever-smokers, (HR $1.37,95 \%$ CI 1.02 to 1.83 ) and among blue-collar workers (HR 1.36, 95\% CI 1.01 to 1.84 ). Among obese participants, there was an indication of increased risk in relation to high strain (HR 2.05, 95\% CI 0.93 to 4.81) but with wide CIs. In other strata, there was an increased risk for CHD in the active group among those with hypertension (HR 1.50, $95 \%$ CI 1.00 to 2.33; table 2).
For the follow-up period, there were 549 events due to stroke. In the total population, there was no increased risk for stroke in any of the JDC categories. In the stratified analyses, those with self-reported stress at baseline seem to have increased risk, in the active group (HR $1.98,95 \%$ CI 1.09 to 4.05$)$ and in the passive group as well (HR 2.15, 95\% CI 1.17 to 4.44; table 2).

In the additional analyses, participants with 5 years latency time, the results were similar. The risk for CHD among participants with high strain was slightly higher (HR 1.34, 95\% CI 1.00 to 1.80; table 3). In the final full model, with adjusted age, adiposity, diabetes, smoking and hypertension, there was an indication of increased risk of CHD in relation to high strain (HR 1.29, 95\% CI 0.97 to 1.72 ). There were no increased risks for stroke.

Further additional analyses explored the relationship between low control and high demands. There was a clear relation between low control and increased risk for CHD (table 4). This was found among all participants, including smokers and in participants without hypertension, without diabetes, without self-reported stress or with BMI $<30$. There were no clear signs of high demands and risk for CHD. There were no significant relations between low control or high demands and the risk for stroke (table 4).

\section{DISCUSSION}

\section{Principal findings}

In line with the other studies, an increased risk for CHD was found in relation to high strain, job strain. Of interest is that job strain risks increased further among 
Table 2 Cox regression models of 6070 men followed from 1974 to 1977 until event or until 75 years of age

\begin{tabular}{|c|c|c|c|c|}
\hline \multirow[b]{2}{*}{ Strain group } & \multicolumn{2}{|c|}{ Coronary heart disease } & \multicolumn{2}{|l|}{ Stroke } \\
\hline & $\mathrm{N}$ (N events) & HR (95\% Cl) & $\bar{N}$ (N events) & HR $(95 \% \mathrm{Cl})$ \\
\hline All & $6070(1052)$ & & $6070(549)$ & \\
\hline Active & $2357(384)$ & $1.06(0.85$ to 1.32$)$ & $2357(208)$ & $0.91(0.70$ to 1.22$)$ \\
\hline High strain & $671(131)$ & $1.31(1.01$ to 1.70$)$ & $671(64)$ & $1.05(0.74$ to 1.48$)$ \\
\hline Passive & $2363(433)$ & $1.23(1.00$ to 1.53$)$ & $2363(212)$ & $0.96(0.74$ to 1.28$)$ \\
\hline Ever-smokers & 4350 (826) & & $4350(406)$ & \\
\hline Active & $1650(277)$ & $1.00(0.78$ to 1.29$)$ & $1650(152)$ & $0.87(0.64$ to 1.20$)$ \\
\hline High strain & 499 (109) & $1.37(1.02$ to 1.83$)$ & $499(46)$ & $0.92(0.62$ to 1.38$)$ \\
\hline Passive & $1723(361)$ & $1.31(1.03$ to 1.68$)$ & $1723(158)$ & $0.90(0.66$ to 1.25$)$ \\
\hline Never-smokers & $1437(184)$ & & $1437(113)$ & \\
\hline Active & $607(88)$ & $1.21(0.76$ to 1.99$)$ & $607(46)$ & $1.11(0.61$ to 2.18$)$ \\
\hline High strain & $141(18)$ & $1.04(0.55$ to 1.96$)$ & $141(13)$ & 1.39 (0.63 to 3.08$)$ \\
\hline Passive & $518(57)$ & 0.90 (0.55 to 1.52$)$ & $518(42)$ & $1.18(0.64$ to 2.35$)$ \\
\hline Blue-collar workers & $3020(555)$ & & 3020 (279) & \\
\hline Active & $41(7)$ & $1.04(0.44$ to 2.11$)$ & $41(5)$ & $1.30(0.45$ to 2.906$)$ \\
\hline High strain & $492(101)$ & $1.36(1.01$ to 184$)$ & $53(492)$ & $1.22(0.82$ to 1.82$)$ \\
\hline Passive & $2008(372)$ & $1.20(0.94$ to 1.55$)$ & $2008(75)$ & $0.93(0.68$ to 1.30$)$ \\
\hline White-collar workers & 3050 (497) & & $3050(270)$ & \\
\hline Active & $2316(377)$ & $1.14(0.80$ to 1.71$)$ & $2316(203)$ & $0.93(0.60$ to 1.54$)$ \\
\hline High strain & $179(30)$ & 1.15 (0.69 to 1.92$)$ & $179(11)$ & $0.63(0.29$ to 1.30$)$ \\
\hline Passive & $355(612)$ & $1.24(0.80$ to 1.95$)$ & $355(37)$ & 1.16 (0.68 to 2.06$)$ \\
\hline Self-reported stress at baseline & $2177(381)$ & & 2177 (201) & \\
\hline Active & $1014(170)$ & $1.01(0.70$ to 1.49$)$ & $1014(98)$ & 1.98 (1.09 to 4.05$)$ \\
\hline High strain & $236(47)$ & 1.28 (0.82 to 2.02$)$ & $236(20)$ & $1.92(0.92$ to 4.28$)$ \\
\hline Passive & $722(131)$ & $1.13(0.78$ to 1.69$)$ & $722(73)$ & $2.15(1.17$ to 4.44$)$ \\
\hline No self-reported stress at baseline & $3742(381)$ & & $3742(330)$ & \\
\hline Active & 1304 (203) & $1.00(0.77$ to 1.32$)$ & $1304(105)$ & $0.67(0.49$ to 0.94$)$ \\
\hline High strain & $411(77)$ & $1.23(0.89$ to 1.70$)$ & $411(40)$ & $0.84(0.56$ to 1.26$)$ \\
\hline Passive & $1568(635)$ & $1.21(0.94$ to 1.58$)$ & $1568(131)$ & $0.72(0.53$ to 1.00$)$ \\
\hline Hypertension at baseline & $1341(314)$ & & $1341(201)$ & \\
\hline Active & 512 (129) & 1.50 (1.00 to 2.33$)$ & $512(78)$ & $0.86(0.56$ to 1.35$)$ \\
\hline High strain & $160(37)$ & 1.37 (0.84 to 2.29$)$ & $160(22)$ & $0.79(0.45$ to 1.38$)$ \\
\hline Passive & $517(122)$ & $1.41(0.94$ to 2.20$)$ & $517(74)$ & $0.81(0.53$ to 1.29$)$ \\
\hline No hypertension at baseline & $4715(736)$ & & 4715 (347) & \\
\hline Active & $1840(254)$ & $0.93(0.72$ to 1.21$)$ & 1840 (129) & $0.96(0.68$ to 1.39$)$ \\
\hline High strain & $509(94)$ & $1.30(0.96$ to 1.76$)$ & $509(42)$ & $1.21(0.78$ to 1.88$)$ \\
\hline Passive & $1842(311)$ & $1.18(0.93$ to 1.53$)$ & $1842(138)$ & $1.07(0.76$ to 1.55$)$ \\
\hline Body mass index $<30$ & 5544 (938) & & 5544 (499) & \\
\hline Active & 2188 (343) & $0.99(0.79$ to 1.25$)$ & $2188(196)$ & $0.97(0.72$ to 1.31$)$ \\
\hline High strain & $598(113)$ & $1.23(0.94$ to 1.62$)$ & $598(57)$ & $1.08(0.75$ to 1.57$)$ \\
\hline Passive & $2150(387)$ & $1.18(0.95$ to 1.48$)$ & $2150(190)$ & $0.99(0.74$ to 1.34$)$ \\
\hline Body mass index $\geq 30$ & $516(113)$ & & $516(50)$ & \\
\hline Active & $167(41)$ & $1.92(0.98$ to 4.21$)$ & $167(12)$ & $0.54(0.23$ to 1.33$)$ \\
\hline High strain & $70(17)$ & 2.05 (0.93 to 4.81$)$ & $70(7)$ & $0.88(0.31$ to 2.35$)$ \\
\hline Passive & $209(46)$ & $1.76(0.90$ to 3.84$)$ & $209(22)$ & $0.83(0.40$ to 1.91$)$ \\
\hline No diabetes at baseline & 5900 (989) & & $5900(515)$ & \\
\hline Active & 2292 (357) & $1.04(0.84$ to 1.31$)$ & $2292(194)$ & 0.91 (0.69 to 1.22$)$ \\
\hline High strain & 647 (123) & 1.31 (1.01 to 1.72$)$ & $647(60)$ & $1.05(0.74$ to 1.50$)$ \\
\hline Passive & $2299(411)$ & $1.24(1.00$ to 1.55$)$ & $2299(200)$ & $0.97(0.73$ to 1.30$)$ \\
\hline Diabetes at baseline & $170(63)$ & & $170(34)$ & \\
\hline Active & $65(27)$ & $1.26(0.56$ to 3.39$)$ & $65(14)$ & 1.02 (0.36 to 3.59$)$ \\
\hline High strain & $24(8)$ & 1.08 (0.37 to 3.28$)$ & $24(4)$ & $0.96(0.23$ to 4.09$)$ \\
\hline Passive & $64(22)$ & $1.00(0.43$ to 2.73$)$ & $64(12)$ & $0.96(0.33$ to 3.43$)$ \\
\hline
\end{tabular}

ever-smokers, obese participants and among participants with low socioeconomic status. Active participants with hypertension also ran an increased risk for CHD. There was also a clear association between low control and increased risk for CHD. Of interest, even if it is a negative report, is that there was no increased risk for stroke 
Table 3 Cox regression models of 6070 men followed from 1974 to 1977 until event or until 75 years of age

\begin{tabular}{|c|c|c|c|c|}
\hline \multirow[b]{2}{*}{ Strain group } & \multicolumn{2}{|c|}{ Coronary heart disease } & \multicolumn{2}{|l|}{ Stroke } \\
\hline & $\bar{N}$ (N events) & HR $(95 \% \mathrm{Cl})$ & $\bar{N}$ (N events) & HR (95\% Cl) \\
\hline Low strain & $642(85)$ & 1.00 & $642(60)$ & 1.00 \\
\hline Active & 2247 (312) & $1.08(0.85$ to 1.38$)$ & 2275 (189) & 0.93 (0.70 to1.25) \\
\hline High strain & 630 (109) & 1.29 (0.97 to 1.72$)$ & $640(54)$ & 0.91 (0.63 to 1.32$)$ \\
\hline Passive & $2208(351)$ & $1.22(0.97$ to 1.56$)$ & 2248 (190) & 0.94 (0.70 to 1.26$)$ \\
\hline
\end{tabular}

Participants with events for the first 5 years after baseline are excluded. Models adjusted for age, adiposity, diabetes, smoking and hypertension.

in most of the JDC groups. In the strata with high levels of self-reported stress, there was an increased risk for stroke in all job-demand categories.

\section{Methodological considerations}

This study has several strengths, a general population sample with a long period of follow-up and use of a national mortality register and hospital discharge register with high coverage. The assessment of psychosocial stress is based on occupations, which probably is less biased than self-reports of demand and control. Furthermore, the population was in their 50s at baseline, meaning that they are quite stable in their occupations. Finally, the study comprises only men which limit the external validity.

The regression models have been adjusted for age. The study population comprised only men. In the literature, it has been discussed that further adjustments for different lifestyle factors marginally decreased the risk estimates, which is in line with the findings from a large meta-analyses. ${ }^{3}$ There is also a possibility that smoking, adiposity and hypertension can be part of the causal chain act and hence stratifications are to be preferred. Furthermore, there were no separate adjustments for socioeconomic position. The reason is that the exposure for psychosocial stress is based on occupational titles and the socioeconomic position is part of the occupational classification. However, in the stratified analysis, the risk for CHD was increased among blue-collar workers (low socioeconomic status), but not among the white-collar workers (high socioeconomic status). In the literature, the JDC model mostly predicts to ill health associations among blue-collar workers, often men. $^{2} 17^{21-24}$ One plausible explanation is that the development of the JDC model was mainly conducted among male blue-collar jobs, and is consequently adjusted to such job characteristics. When broadening study populations, more conflicting findings emerge. For example, little support has been found for female high strain-related ill health. ${ }^{25}$

\section{The effect of psychosocial stress}

It is evident from this study that high strain and the passive dimension increase the risk for CHD. It is of interest that low control, the common denominator for job strain and the passive dimension, was clearly related to increased risk for CHD.

The results from the present study indicate that exposure to occupational psychosocial stress does not increase the risk for stroke. The study is rather large, with 549

Table 4 Cox regression models of 6070 men followed from 1974 to 1977 until event or until 75 years of age showing hazard ratios for low control and high demands in relation to coronary heart disease and stroke for different subgroups

\begin{tabular}{|c|c|c|c|c|}
\hline \multirow[b]{2}{*}{ Subgroup } & \multicolumn{2}{|c|}{ Coronary heart disease } & \multicolumn{2}{|l|}{ Stroke } \\
\hline & $\begin{array}{l}\text { Low control } \\
\text { vs high control }\end{array}$ & $\begin{array}{l}\text { High demands } \\
\text { vs low demands }\end{array}$ & $\begin{array}{l}\text { Low control } \\
\text { vs high control }\end{array}$ & $\begin{array}{l}\text { High demands } \\
\text { vs low demands }\end{array}$ \\
\hline All & 1.19 (1.06 to 1.35$)$ & $0.94(0.84$ to 1.07$)$ & 1.05 (0.89 to 1.24$)$ & $0.97(0.82$ to 1.15$)$ \\
\hline Never-smokers & $0.80(0.60$ to 1.07$)$ & $1.27(0.95$ to 1.71$)$ & $1.13(0.78$ to 1.64$)$ & $1.02(0.70$ to 1.48$)$ \\
\hline Ever-smokers & 1.32 (1.15 to 1.52$)$ & $0.87(0.76$ to 1.00$)$ & 1.01 (0.83 to 1.23$)$ & 0.95 (0.79 to 1.16$)$ \\
\hline No hypertension & $1.28(1.11$ to 1.48$)$ & 0.88 (0.76 to 1.02$)$ & $1.14(0.92$ to 1.40$)$ & $0.96(0.78$ to 1.18$)$ \\
\hline Hypertension & $1.02(0.81$ to 1.27$)$ & $1.12(0.89$ to 1.39$)$ & 0.91 (0.69 to 1.20$)$ & $0.98(0.74$ to 1.30$)$ \\
\hline $\mathrm{BMI}<30$ & $1.20(1.05$ to 1.36$)$ & $0.92(0.81$ to 1.04$)$ & $1.03(0.87$ to 1.23$)$ & $1.00(0.84$ to 1.19$)$ \\
\hline $\mathrm{BMI} \geq 30$ & $1.11(0.77$ to 1.61$)$ & $1.25(0.86$ to 1.81$)$ & 1.25 (0.72 to 2.22$)$ & $0.72(0.40$ to 1.26$)$ \\
\hline No diabetes & 1.22 (1.07 to 1.38$)$ & $0.93(0.82$ to 1.05$)$ & 1.06 (0.89 to 1.26$)$ & $0.96(0.81$ to 1.14$)$ \\
\hline Diabetes & $0.85(0.51$ to 1.40$)$ & 1.21 (0.74 to 2.01$)$ & $0.95(0.47$ to 1.87$)$ & 1.04 (0.52 to 2.07$)$ \\
\hline No stress & 1.21 (1.04 to 1.42$)$ & 0.91 (0.78 to 1.06$)$ & 0.99 (0.80 to 1.23$)$ & $0.90(0.73$ to 1.12$)$ \\
\hline Self-reported stress & $1.16(0.95$ to 1.42$)$ & $0.96(0.78$ to 1.17$)$ & 1.15 (0.87 to 1.52$)$ & 1.04 (0.79 to 1.39$)$ \\
\hline Blue-collar workers & $1.23(0.98$ to 1.56$)$ & $1.15(0.93$ to 1.41$)$ & $0.96(0.72$ to 1.31$)$ & $1.31(0.97$ to 1.73$)$ \\
\hline White-collar workers & 1.06 (0.84 to 1.33$)$ & $1.00(0.80$ to 1.26$)$ & 1.04 (0.75 to 1.40$)$ & 0.83 (0.62 to 1.12$)$ \\
\hline
\end{tabular}


stroke events, and there was no increased risk in different lifestyle strata. Previously, the association with job strain has been unclear with positive ${ }^{91012}$ and negative studies. ${ }^{11}$ There is probably a publication bias as studies with no or weak associations may not be published, as it has been shown for job strain and CHD. ${ }^{3}$ Hypertension has been associated with occupational psychosocial stress, especially among men. ${ }^{26}$ However, job strain was not associated with stroke among men with hypertension at baseline. Hence, the present study indicates that stroke has a different pattern of risk factors compared with CHD.

Self-reported stress has been associated with stroke, in cohort studies ${ }^{5} 2728$ and in case-control studies. ${ }^{6}{ }^{29}$ Self-reported stress is a global composite item reflecting occupational and non-occupational exposure. In the present study, increased risks for stroke were among participants reporting stress at baseline and belonging to either the active, high strain or passive strata (compared with low strain). This may indicate an interaction between occupational and non-occupational stress in relation to stroke.

One limitation of our study is that there was only one assessment of the exposure, the occupational psychosocial stress. There are indications in the literature that psychosocial stress occurs late in the causal chain for stroke as indicated by the observation that studies with short period of follow-up have higher risks of stroke in relation to psychosocial stress. ${ }^{8}{ }^{9}$ We have a rather long observation period, which may result in low risk estimates due to misclassification of the exposure.

Another limitation of this study is that the sample consisted only of men. Previous studies have indicated that health outcomes differ between men and women when exposed to JDC. ${ }^{8-11} 22{ }^{25}$ Since the cohort was established with only men, it was not possible to include women in our study, but we recommend that future similar analyses include women as to investigate gender differences.

The study confirms the previous findings of an association with job strain and risk for CHD. Compared with some other studies, the risk levels were quite modest, which may reflect non-differential misclassification of the exposure assessment or may reflect the true underlying risk. ${ }^{30}$ There was a slight interaction with lifestyle factors, especially smoking and to some extent also obesity, as the risks were further increased among smoking and obese participants. A positive interaction with smoking and obesity was recently shown in a meta-analysis. ${ }^{4}$ A finding that needs to be replicated is that active participants with hypertension had a high risk for CHD.

\section{CONCLUSIONS}

Exposure to occupational psychosocial stress defined as job strain increased the risk for CHD, especially among smokers and blue-collar workers. Low control was also related to increased risk for CHD. There was no increased risk for stroke in any of the JDC categories.
Contributors All authors were responsible for the design, drafting of the manuscript and for the final approval of the manuscript. In addition, LS performed the statistical analyses.

Funding The study was funded by the Swedish Research Council (VR), the Swedish Research Council for Health, Working Life and Welfare (FORTE) and the Swedish Heart and Lung Foundation.

Competing interests None.

Ethics approval Ethics Committe for Medical Research at University of Gothenburg.

Provenance and peer review Not commissioned; externally peer reviewed.

Data sharing statement This is a large general population study which has been followed for decades. There are a lot of unpublished data in the dataset. Scientific cooperation around this study is possible.

Open Access This is an Open Access article distributed in accordance with the Creative Commons Attribution Non Commercial (CC BY-NC 3.0) license, which permits others to distribute, remix, adapt, build upon this work noncommercially, and license their derivative works on different terms, provided the original work is properly cited and the use is non-commercial. See: http:// creativecommons.org/licenses/by-nc/3.0/

\section{REFERENCES}

1. Rosengren A, Hawkens S, Ounpuu S, et al. Association of psychosocial risk factors with risk of acute myocardial infarction in 11 119 cases and 13648 controls from 52 countries (the INTERHEART study): case-control study. Lancet 2004;364:953-62.

2. Karasek RA. Job demands, job decision latitude, and mental strain: implications for job redesign. Admin Sci Q 1979;24:285-307.

3. Kivimäki M, Nyberg ST, Batty GD, et al. Job strain as a risk factor for coronary heart disease: a collaborative meta-analysis of individual participant data. Lancet 2012;380:1491-7.

4. Kivimäki M, Nyberg ST, Fransson El, et al. Associations of job strain and lifestyle factors with risk of coronary artery disease: a meta-analysis of individual participant data. Can Med Assoc J 2013;185:763-9.

5. Harmsen $P$, Lappas $G$, Rosengren $A$, et al. Long-term risk factors for stroke: twenty-eight years of follow-up of 7457 middle-aged men in Göteborg, Sweden. Stroke 2006;37:1663-7.

6. O'Donnell MJ, Xavier D, Liu L, et al. Risk factors for ischaemic and intracerebral haemorrhagic stroke in 22 countries (the INTERSTROKE study): a case-control study. Lancet 2010;376:112-23.

7. Virtanen SV, Notkola V. Socioeconomic inequalities in cardiovascular mortality and the role of work: a register based study of Finnish men. Int J Epidemiol 2002;31:614-21.

8. Toivanen S, Hernström Ö. Is the impact of job control on stroke independent of socioeconomic status? A large scale study of the Swedish working population. Stroke 2008;39:1321-3.

9. Kivimäki M, Gomeno D, Ferrie JE, et al. Socioeconomic position, psychosocial work environment and cerebrovascular disease among women: the Finnish public sector study. Int $J$ Epidemiol 2009;38:1265-71.

10. Kuper $\mathrm{H}$, Adami HO, Theorell $\mathrm{T}$, et al. The socioeconomic gradient in the incidence of stroke: a prospective study in middle-aged women in Sweden. Stroke 2007;38:27-33.

11. André-Petersson L, Engström G, Hagberg B, et al. Social support at work and the risk for myocardial infarction and stroke in women and men. Soc Sci Med 2007;64:830-41.

12. Tsutsumi A, Kayaba K, Kario K, et al. Prospective study on occupational stress and risk of stroke. Arch Intern Med 2009;169:56-61.

13. Wilhelmsen L, Berglund G, Elmfeldt D, et al. The multifactor primary prevention trial in Gothenburg, Sweden. Eur Heart J 1986;7:279-88.

14. Rosengren A, Hauptman PJ, Lappas G, et al. Big men and atrial fibrillation: effects of body size and weight gain on risk of atrial fibrillation in men. Eur Heart $J$ 2009;30:1113-20.

15. Novak M, Torén K, Lappas G, et al. Socioeconomic status and incidences of ischemic and hemorrhagic stroke in Swedish men: a population-based 35-year prospective follow-up study. Eur J Epidemiol 2013;28:697-704.

16. Arbetsmarknadsstyrelsen. Nordisk yrkesklassificering: Systematisk förteckning över yrkesområden, yrkesgrupper, yrkesfamiljer och individualyrken med kodnummer och definitioner. Stockholm, Sweden: Arbetsmarknadsstyrelsen, 1974. 
17. Johnson JV, Stewart W, Hall EM, et al. Long-term psychosocial work environment and cardiovascular mortality among Swedish men. Am J Public Health 1996;86:324-31.

18. Fredlund $\mathrm{P}$, Hallqvist $\mathrm{J}$, Diderichsen F. Psykosocial yrkesexponeringsmatris. Arbete och Hälsa 2000;11:1-37. [In Swedish].

19. Giang KW, Björck L, Novak $M$, et al Stroke and CHD-Predictive power of standard risk factors until old age. Long term cumulative risk study among men in Gothenburg, Sweden. Eur Heart $J$ 2013;34:1068-74.

20. Grambsch PM, Therneau TM. Proportional hazards tests and diagnostics based on weighted residuals. Biometrika 1994;81: $515-26$.

21. Kuper $\mathrm{H}$, Marmot $\mathrm{M}$, Hemingway $\mathrm{H}$. Systematic review of prospective cohort studies of psychosocial factors in the etiology and prognosis of coronary heart disease. Semin Vasc Med 2002;2:266-314.

22. Van der Doef M, Maes S. The job demand-control (-support) model and psychological well-being: a review of 20 years of empirical research. Work Stress 1999;2:87-114.

23. Häusser JA, Mojzisch AM, Niesel M, et al. Ten years on: a review of recent research on the job demand-control (-support) model and psychological well-being. Work Stress 2010;24:1-35.
24. Bosma $\mathrm{H}$, Peter R, Siegrist J, et al. Two alternative job stress models and the risk of coronary heart disease. Am J Public Health 1988;88:68-74.

25. Belkic KL, Landsbergis PA, Schnall PL, et al. Is job strain a major source of cardiovascular disease risk? Scand J Work Environ Health 2004;30:85-128.

26. Diène $E$, Fouquet $A$, Esquiol $Y$. Cardiovascular diseases and psychosocial factors at work. Arch Cardiovasc Dis 2012;105:33-9.

27. Truelsen T, Nielsen N, Boysen G, et al. Self-reported stress and risk of stroke: the Copenhagen City Heart Study. Stroke 2003;34:856-62.

28. Öhlin B, Nilsson PM, Nilsson J-Å, et al. Chronic psychosocial stress predicts long-term cardiovascular morbidity and mortality in middle-aged men. Eur Heart J 2004;25:867-73.

29. Jood K, Redfors $\mathrm{P}$, Rosengren A, et al. Self-perceived psychological stress and ischemic stroke: a case-control study. BMC Med 2009; 7:53.

30. Netterstrøm B, Kristensen TS, Jensen G, et al. Is the demand-control model still a useful tool to assess work-related psychosocial risk for ischemic heart disease? Results from 14 year follow up in the Copenhagen City Heart Study. Int J Occup Med Environ Health 2010;23:217-24. 